\title{
Ethics and geographical equity in health care
}

Nigel Rice and Peter C Smith University of York

\begin{abstract}
Important variations in access to health care and health outcomes are associated with geography, giving rise to profound ethical concerns. This paper discusses the consequences of such concerns for the allocation of health care finance to geographical regions.

Specifically, it examines the ethical drivers underlying capitation systems, which have become the principal method of allocating health care finance to regions in most countries. Although most capitation systems are based on empirical models of health care expenditure, there is much debate about which needs factors to include in (or exclude from) such models. This concern with legitimate and illegitimate drivers of health care expenditure reflects the ethical concerns underlying the geographical distribution of health care finance.
\end{abstract}

(Fournal of Medical Ethics 2001;27:256-261)

Keywords: Health economics; resource allocation; ethics of regional health care finance; capitation systems

\section{Introduction}

Among the many objectives set for health care systems by policy-makers, the pursuit of concepts such as equal access to health care, or equal health outcomes, frequently play an important role. The prominence of such objectives suggests that a concern with equity is an important element of the ethical bases underlying the design of health care systems. The examples of equal access and equal outcomes reflect, respectively, the classic Aristotelian principles of horizontal and vertical equity in respect of health care. A concern with equal access suggests equal treatment of equals (horizontal equity), whilst a concern with equal health outcome suggests that those who are different in relevant respects (such as life expectancy) should in some sense be treated proportionately differently (vertical equity).

In making either of these principles operational, geography becomes important for three reasons. First, many systems of health care are organised on a geographical basis. Issues of territorial equity therefore become central to the distribution of health care resources. Second, whatever system of health care is in place, health care facilities such as hospitals and clinics are concentrated at specific locations, implying that geographical considerations may be of central importance in determining access to health care and health outcomes. Third, there is considerable evidence that geographical inequalities in health, in the form of "area effects", may exist beyond social class and income inequalities.

In this paper we discuss the ethical issues that arise when a citizen's health care insurance arrangements are based purely on area of residence. The central issue we address is how to reflect ethical principles in the allocation of health care finance to geographical areas. In order to address this problem we must first summarise the principal geographical influences on health and health care utilisation (section 2). In section 3 we examine the principles that link notions of geographical equity to health care finance. Section 4 examines the ethical drivers underlying methods of allocating health care finance geographically. Some brief conclusions are given in section 5 .

\section{Geography, health and health care}

Geographical considerations play a crucial role in influencing health. ${ }^{1}$ Geography may directly affect an individual's health status, through environment or less tangible geographical effects such as an area's social capital; geography may play an important role in the nature of health care delivered, through historical and cultural inheritances and regional price variations; and the geographical distribution of health care facilities may affect utilisation, through differential opportunity of access to services. These are considered in turn.

AREA EFFECTS ON HEALTH

There are several plausible area effects on an individual's health. Most obviously, the physical environment might be an important determinant of health variations. The impact on health of variations in local economic conditions, such as the dominant type of employment, might also create an important area effect. Inadequacies in social support systems, such as transport, social care and education services, might have adverse implications for local health outcomes. Less tangibly, local culture might affect lifestyle in numerous ways (such as diet and smoking), giving rise to an apparent area effect on health. Interest in reducing area health inequalities is likely to stimulate a geographical policy response (such as the "health action zones" implemented in England).

AREA EFFECTS ON HEALTH CARE PRODUCTION

Input prices can vary substantially between areas. This affects the aggregate level of finance required 
to deliver a standard level of health care. However, it might also have an important influence on the way that health care is organised. For example, rural and urban areas present quite different challenges for the optimal design of health services. Given increasing returns to scale, it becomes more costly to deliver the same level of hospital care to rural areas as in urban areas. Rural areas may therefore not secure the economies of scale obtained in urban areas, and might be offered extra finance in order to continue to provide a standard level of care (for example, in the form of small hospitals). However, all systems of health care recognise that-once rurality exceeds a certain level-it becomes impractical to deliver the same services as are enjoyed in urban areas. So very rural communities may suffer a lower level of services than their urban counterparts, may have to trave further to secure such services, or may receive health care in a different manner (for example through greater use of telemedicine). ${ }^{2}$ The issue of rurality exemplifies the trade-off that exists between equity and efficiency in the allocation of health care resources. The pursuit of efficiency, in the sense of equalising the marginal cost of a unit of health gain, must be moderated by equity considerations. ${ }^{3}$

\section{AREA EFFECTS ON HEALTH CARE UTILISATION}

There is strong evidence to suggest that geographical access to services has a profound effect on health care utilisation. ${ }^{4}$ Such effects might take the form of "supplier induced demand", in the sense that, in areas with relatively high provision of health care, individuals might be "induced" to make more use of services than their counterparts in less well provided areas. Conversely, areas with low levels of provision might exhibit "supplier suppressed demand". Further, there also may be important areawide cultural influences on the use of health services that might, for example, influence a threshold of ill health below which individuals choose not to seek medical intervention. The extent to which the system of health care finance should seek to address such inequalities will be heavily influenced by equity objectives. ${ }^{5}$

There is substantial evidence that area effects are important. For example-after every attempt is made to account for measurable differences in clinical need-rural areas exhibit lower levels of hospital utilisation and have poorer health outcomes than their urban counterparts. ${ }^{67}$ Such geographica disparities might arise from any or all of the three sources noted above. If they give rise to ethical concern, the geographical allocation of health care finance becomes a central instrument for making an appropriate adjustment to health care resource levels.

\section{Geographical equity in health care finance}

Outside of the United States, with its uniquely pluralistic tradition, systems of health care finance in the developed world can be considered under four broad headings: managed competition between competing insurers (as, for example, in Belgium, the Netherlands, Germany and Switzerland); compulsory social insurance based on sector of employment (as in France, Japan and Austria); centralised public systems of insurance, with accountability usually devolved to local management boards (as in the United Kingdom, New Zealand and many states in Australia and Canada), and devolved public sector systems of insurance, in which local governments assume responsibility for organising health care (as in Scandinavia, Spain and Italy).

Geography is a key element in the organisation of many of these systems of finance, most obviously those within the public sector, in which the pursuit of some concept of territorial equity is often a central policy objective.

In this section, we examine the two principal ethical issues that arise when health care is organised geographically: namely, who is to pay for the health care system, and to what extent should the level of financial resources be allowed to vary between areas. We assume an individual is compulsorily placed in an insurance risk pool comprising all citizens living in the defined administrative area, that may be a large region with many millions of inhabitants, or a small municipality. The risk pool is responsible for financing and purchasing all relevant health care for its members.

Suppose first that there exists a national "standard" package of health care, that all area risk pools seek to offer. The chosen package implies a certain level of expected expenditure for every individual, which we term his or her "spending need". This will of course depend on the individual's personal characteristics, such as age, but will usually presume a uniform level of efficiency and service quality on the part of the health service. The personal characteristics to be taken into account in calculating the expected expenditure on an individual will in some part be determined by society's ethical preferences, as discussed further in section 4. Because individuals differ in their health care needs, so in general do local areas. We can define the health care expenditure needs of a region as the expected costs of delivering the standard package of care given the personal characteristics of its citizens, assuming a given level of productive efficiency.

We first assume that the costs of delivering the standard package of care must be borne in their entirety by the local area, and that the sole source of revenue is a local tax-base. The tax-base might be property values if revenue is raised from local property taxation, or local employment income if raised from a payroll tax. Then, assuming no revenue from any other source, the local health care tax rate (or insurance premium rate) is given by the ratio of health care costs to the size of the tax-base. In general, therefore, the costs to identical citizens living in different areas of insuring a standard package of health care will vary substantially depending on (a) 
the population health care needs and (b) the revenue-base of the areas in which they live.

An alternative extreme arrangement would be that a uniform premium rate must be charged in all areas, and areas must then deliver some package of health care within the revenue this generates. The revenue available to an area will then depend solely on the size of its tax-base, with no reference to health care needs. The area will therefore either have to offer an inferior package of care when standard expenditure needs exceed revenue, or be able to offer superior health care when revenue exceeds standard needs. Arrangements such as these, in which each area-based risk pool depends purely on its own resources, can be thought of as a system of pure risk-fragmentation between areas.

\section{Ability to pay}

The implied variations in insurance premiums and health care packages brought about by pure risk-fragmentation has almost universally been considered unacceptable on ethical grounds. In general it would lead to areas with high health care needs and poor revenue-bases offering more restricted health care, higher copayments (whereby the insured person pays a contribution towards the supplier's charges) or higher premiums than their healthier, richer counterparts. Almost all geographically based systems of health care therefore have implicit or explicit objectives that reflect horizontal and vertical equity concerns relating to the geographical distribution of resources. ${ }^{8}$

It is less common to encounter explicit objectives relating to the financial contribution to health care made by regions. However, they exist implicitly, in the sense that almost all societies insist that individuals' contributions to health care funding should be mainly according to ability to pay, rather than benefits received. This principle rules out direct charges to the users of health care as a major source of finance. In this paper, we are interested in the extent to which, after taking account of all other relevant factors such as income and wealth, payment for health care varies according to where a citizen lives.

In centralised public health care systems, funded by national taxation, geographical variation in payment is eliminated by applying national rates of taxation to all local tax-bases. More interesting is the case where some discretion in local tax rates is permitted, as in the devolved system of health care used in Scandinavian local government. Here the ethical principles relating to health care must be integrated with the principle of local freedom intrinsic to local government. ${ }^{9}$ Under these arrangements, a concept of equal access (for equal need) may need to be amended to one of equal opportunity for localities to deliver a standard package of care at a standard premium. Local areas may then have the freedom collectively to vary some elements of the package of care and premium rate. ${ }^{10-12}$ If a locality chooses to vary the package, the usual arrangement is that the entire burden of any extra expenditure falls on the locality, in the form of additional premium or user charges.

The principal policy instrument for securing geographical equity objectives has been the development of various revenue sharing schemes, which seek to compensate risk pools for variations in health care needs and resource bases. If the policy objective is to secure an identical rate of premium for all areas, the usual procedure is to apply some national standard premium rate to each local tax-base. The difference between the notional revenue this yields and the area's assessed spending needs is the contribution of the area to the revenue-sharing pool (which becomes a receipt if spending needs exceed the notional revenue). For a self-funding system of health care, the sum of all receipts must equal the sum of contributions to the revenue-sharing pool. In centralised systems, revenue comes from national or state-wide sources, such as general taxation. Under these circumstances, there is no need to seek to equalise insurance payments, as these form part of the national tax structure and are therefore already equalised. The policy problem is therefore to develop estimates of local spending needs, that then form the basis for financial allocations to localities without reference to local tax-bases.

If necessary, an area's revenue-base is usually readily observed. The principal technical difficulty in implementing revenue-sharing schemes is therefore the estimation of an area's health care spending needs. In attempting to address this issue, numerous risk adjustment schemes have been developed. ${ }^{8}$ We summarise work in this area in the next section.

Before doing so, it is important to note that, in addition to equity arguments, there may be important arguments relating to political solidarity for seeking to equalise health care packages and premium rates. For example, inferior local packages of public sector health care may induce richer, healthier individuals to resort to private insurance, thereby possibly diluting their commitment to continue contributing to a public sector system from which they enjoy no benefits. The public funding of the health care system may become unviable. Similarly, to avoid subsidising the poor and the sick, the rich and healthy may flee more deprived areas, leaving behind a tax-base that cannot support an acceptable system of health care in the absence of any revenue sharing.

\section{Heterogeneity}

On the other hand, there are those who may argue that the heterogeneity between areas implicit in a system of pure risk-fragmentation is not a cause for concern. The Tiebout model of local government ${ }^{13}$ suggests that citizens might migrate to the locality most closely offering their preferred mix of health care, insurance premium and housing costs, and that no transfers between localities are required. For example, if premium revenues are raised from a local tax-base, high levels of local premiums (or inferior local health care) might be reflected in lower property values. Some or all of a deprived 
area's disadvantage may therefore be compensated in the form of lower housing costs. ${ }^{14}$ In practice, the influence of such extreme laissez faire approaches has been minimal outside the United States.

\section{Calculating spending needs}

In most systems of health care, health care expenditure needs are estimated through the use of capitation payments. A capitation payment is defined as the amount of prospective health care finance attached to an individual for a specified period of time. Most systems employ some form of risk adjustment that seeks to vary capitation payments on the basis of individual characteristics, reflecting expenditure needs.

There is an enormous range of determinants of expected health care expenditure for an individual. These include the individual's social and environmental circumstances as well as health status. There may also be important structural reasons (such as remoteness and language barriers) that lead to higher costs in some areas than in others. Such factors should in principle be taken into account when designing a capitation system. In practice, the extent to which this is possible has been severely constrained by data availability and methodological limitations. ${ }^{8}$ Moreover there may be some determinants of expenditure on an individual that a capitation system should not take into account. For example, many systems of health care do not compensate purchasers for variations in clinical practice from some assumed norm.

This implies that-from a capitation perspectivedeterminants of expenditure on an individual can be divided into the legitimate (which the scheme should take into account) and the illegitimate (which the scheme should not take into account) The criteria for deciding whether a determinant is legitimate or not should in principle be based on the ethical framework underlying the health care system.

Almost all capitation schemes use empirical utilisation data as the basis for risk adjustment. ${ }^{8}$ That is, the capitation for a person with particular characteristics is some estimate of average historical expenditure on similar individuals. Such capitation schemes are intrinsically conservative. They implicitly assume that the average level of care as historically delivered to each type of person equates to the desired package of health care. This conservatism reflects an understandable reluctance to define explicitly what constitutes the "standard" package of care to be covered. Instead, policy is developed on the assumption that whatever is currently on average delivered by the health care system is de facto the standard.

Use of historical spending averages takes no account of the possibility that for some population groups there may exist unmet health care need. Unmet need can be defined as a difference between the desired package of care and the package actually received, and reflects systematic shortfall in the health care expenditure allocated to certain groups of the population. Where an equity concept of "equal access for equal need" is employed, it implies that certain population groups with a particular need are denied the care offered to the rest of the population with that need. The possibility of unmet need, particularly among ethnic minorities and rural communities, has taxed many of those seeking to develop capitation schemes. ${ }^{15-18}$

Ethical concerns relating to unmet need for health care can be summarised under two headings: inequalities of access to health care, and inequalities of outcome, which loosely correspond to concerns about horizontal and vertical equity. Inequalities of access suggest the existence of a population characteristic that is associated with lower observed levels of health care utilisation than the rest of the population, other things being equal. Given society's ethical stance, the characteristic is not considered a legitimate influence on health care spending, and its existence implies horizontal inequity.

Unacceptable inequalities in health outcomes lead to a concern with vertical inequity. ${ }^{19}$ There is a presumption that more health care resources should be directed at the adversely affected population groups. For ethical reasons, there is therefore a personal characteristic that indicates that an individual should secure access to more health care resources than the rest of the population, other things being equal. The chosen characteristic represents a legitimate influence on a capitation payment, and so it should influence capitation payments.

\section{Formidable task}

Deciding whether an observed significant influence on spending is legitimate or illegitimate is in practice a formidable task. For example, suppose that, after adjusting for variations in plausible population characteristics, it is found that some areas of a country exhibit systematically higher levels of spending than others. This may be due to illegitimate factors, such as variations in health care supply. Or it may be due to legitimate variations, caused by variations in needs that cannot be captured in the available measures of population characteristics.

As a result, the extent to which such area-based variations in spending should be reflected in resource allocations has much exercised policymakers. Approaches vary from assuming that all unexplained area variation is illegitimate, and is therefore removed from capitation formulae (as in the United Kingdom) ${ }^{20}{ }^{21}$ to assuming that all area variation is legitimate. This latter approach is adopted in US Medicare capitation payments, which are based in the first instance on an individual's characteristics, such as age, sex and morbidity diagnosis. However, the payments are then adjusted depending on the average riskadjusted health care expenditure in the county of residence..$^{22}$

Geographical resource allocation is further complicated by the possibility that there may be variations in health care input prices between areas, suggesting that the expenditure consequences of 
delivering a standard package of care may vary. An extreme example of this can be observed in England, where it is estimated that input prices are $40 \%$ higher in central London than in most of the rest of the country. ${ }^{23}$ In order to preserve any concept of equity, such variations should be accommodated within a capitation scheme. Yet, as the US Medicare example indicates, often little effort is made to disentangle legitimate price variations from illegitimate utilisation variations between areas.

It is in practice unrealistic to expect that all citizens can be offered identical levels of access to identical modes of health care delivered at identical standards. The ethical principle of equal treatmen for equal need is likely to be tempered by a recognition that health care in (say) highly rural areas must be qualitatively different from its counterpart in urban areas. There cannot be a general hospital on every street corner. To some extent such variations are formally recognised. For example, standards for ambulance response times in England are more relaxed in rural than urban areas. However, the extent to which such variations are considered legitimate for broader aspects of health care is largely a matter of conjecture.

An interesting insight into the distinction between horizontal and vertical equity concepts is offered by recent developments in the English National Health Service (NHS). For many years, geographical resource allocation has sought to offer "equal opportunity of access for equal need", suggesting a concern with horizontal equity ${ }^{24}$ In 1998 however, the government announced an intention to revise the resource allocation criterion to one of "contributing to a reduction in health inequalities", indicating an interest in vertical as well as horizontal equity. This shift implies a concern that current patterns of health care consumption are unsatisfactory, because they do not resolve unacceptable variations in health outcome. It signals a desire to change current patterns of spending, and so empirical observation of existing spending patterns is unlikely to form a useful basis for estimating capitation payments. ${ }^{25}$

\section{Managerial action}

Avoidable health inequalities arise from three broad sources: variations in the quality of health care services; variations in access to services, and variations in factors outside the control of health services, such as wealth, lifestyle and genetic and environmental considerations. There is considerable evidence that many populations suffering poor health outcomes suffer on all three counts. ${ }^{26}$

Poor quality services for disadvantaged populations are in many respects a performance management (rather than resource allocation) issue. The right amount of money may be being spent on such populations, but service organisation and delivery is unsatisfactory. The policy implication is that extra resources are not the principal source of the problem, but rather that the quality defects should be rectified by managerial action. Therefore, there may be no need for any major change to the resource allocation system.

Poor access implies that disadvantaged populations are not receiving some services to which the remainder of the population secures access-that is, there is horizontal inequity. This compromises the validity of existing capitation formulae that are based on empirical links between need and spending, because they will not capture any unmet need. There will therefore be a need both for supplementary resource allocations outside the empirically based capitation formulae and for performance management to ensure that the extra allocations are spent on the intended target-rectifying unmet need.

Poor life chances among disadvantaged populations pose the most fundamental challenge. If the health care system is to tackle health inequalities arising from this source, it must target the vulnerable populations in a way that it has not done hitherto. This may entail offering such populations preferential access to health care, in the form of provision of services not available to other users. In short, addressing health inequalities might require abandonment of the principle of equal access for equal clinical need, in favour of preferential access for those with poorer life chances, and policy might be to implement "positive discrimination" in favour of deprived areas. This redirection of public sector resources might extend well beyond health care to embrace other public services that affect health.

\section{Conclusions}

Implicit in the above discussion is the reality that-in practice-matching the geographical allocation of health care finance to ethical principles is a formidable task. Equity objectives, such as securing equal access to health care for equal need, or securing equality of health outcome, can never be perfectly achievable. In practice, inequalities in provision of health care will always exist, if only because of geographical variations in the costs of reaching services, ${ }^{5}$ and equality of health outcome can be pursued only in part by redeployment of health service resources. The pursuit of efficiency in health care can be viewed as a further ethical concern. Yet policy-makers often lack guidance on the extent to which the pursuit of equity objectives should be tempered by efficiency considerations. ${ }^{27}$

The choice of equity criterion can be used to determine what constitute the legitimate determinants of expenditure to be used in the design of capitation payment formulae. We have nevertheless noted the practical difficulties encountered in making ethical principles operational. Apart from the prosaic problem of data limitations, there is often a methodological difficulty in disentangling legitimate from illegitimate influences on expenditure variation. A further major lacuna in seeking to make ethical policies operational has been the reluctance to specify what constitutes a "standard" package of health care. The use of historical precedent might lead to the perpetuation of serious breaches of the ethical principles citizens wish to see reflected in their systems of health care. 
Notwithstanding these difficulties, we nevertheless believe that the pursuit of equity in the geographical allocation of health care finance is an issue of profound importance. A fairer distribution of funds is desirable for its own sake, in maximising the value that society secures from its investment in health care, and less directly in securing the widespread popular support for publicly funded health services that is needed if they are to remain viable.

\section{Acknowledgements}

Both authors are in part funded by the UK Department of Health. Funding from ESRC grant L128251050 is also acknowledged. We are grateful for the comments of our colleagues Tony Culyer, Katharina Hauck and Rebecca Shaw.

Nigel Rice is Senior Research Fellow, and Peter C Smith is Professor of Economics, at the Centre for Health Economics, University of York, Heslington, York.

\section{References \\ 1 Jones K, Duncan C. Individuals and their ecologies: analysing the geography of chronic illness within a multilevel modelling framework. Health and Place 1995;1:27-40. \\ 2 Kluge EW. The Canadian health care system: an analytical per- spective. Health Care Analysis 1999;7:377-91. \\ 3 Smith P, Burrows R, Dolan P, Shaw R, Williams A, eds. Meas- uring preferences regarding equity and variations in health. uring preferences regarding \\ 4 Goddard M, Smith P. Equity of access to health care services: theory and evidence. Social Science and Medicine 2001 (forthcoming). \\ 5 Birch S, Abelson J. Is reasonable access what we want? Implications of, and challenges to, current Canadian policy on equity in health care. International fournal of Health Services 1993;23:629-53 \\ 6 Watt I, Franks A, Sheldon T. Health and healthcare of rural populations in the UK-is it better or worse? Fournal of Epidemi- ology and Community Health 1994;48:16-21. \\ 7 Campbell N, Elliott A, Sharp L, Ritchie L, Cassidy J, Little J. Rural factors and survival from cancer: analysis of Scottish cancer registrations. British fournal of Cancer 2000;82:1863-6. \\ 8 Rice N, Smith P. Capitation and risk adjustment in health care financing. an international progress report. The Milbank Quar terly 2001;79:81-113.}

9 Rattso J, ed. Fiscal federalism and state-local finance. Cheltenham: Edward Elgar, 1998.

10 Ministry of Social Affairs and Health. The health care system in Finland. Helsinki: Ministry of Social Affairs and Health, 1996.

11 Sørensen RJ, Grytten J. Contract design for primary care physicians: physician location and practice behaviour in small physicians: physician location and practice behaviour in small

12 Andersson, PÅ, Varde E, Diderichsen F. Modelling of resource allocation to health care authorities in Stockholm County. Health Care Management Science 2000; 3:141-9.

13 Tiebout CM. A pure theory of local expenditures. Fournal of Political Economy 1956;66:416-24.

14 Oates W. The effects of property taxes and local public spending on property values: an empirical study of tax capitalization and the Tiebout hypothesis. Fournal of Political Economy1969; 77:957-71.

15 New Zealand Ministry of Health. Personal health funding formula 1996/97. Wellington: Ministry of Health, 1996.

16 New South Wales Health Department. Resource distribution formula technical paper 1998/99 revision. Sydney: New South Wales Health Department, 1999.

17 Goddard M, Smith P. Equity of access to health care. York: Centre for Health Economics, University of York, 1998.

18 Diderichsen F, Varde E, Whitehead M. Resource allocation to health authorities: the quest for an equitable formula in Britain health authorities: the quest for an equitable formula in

19 Mooney G. And now for vertical equity? Some concerns arising from aboriginal health in Australia. Health Economics 1996; 5:99-103.

20 Royston GHD, Hurst JW, Lister EG, Stewart PA. Modelling the use of health services by populations of small areas to inform the allocation of central resources to larger regions. Socio-Economic Planning Sciences 1992;26:169-80.

21 Carr-Hill RA, Sheldon TA, Smith P, Martin S, Peacock S, Hardman G. Allocating resources to health authorities: development of methods for small area analysis of use of inpadievelopment services. British Medical fournal 1994;309:1046-9.

22 Health Care Financing Administration. Medicare+Choice Rates 2000: 45 day notice. Washington: Health Care Financing Administration, 1999

23 Institute for Employment Research. Labour market forces and NHS provider costs. Coventry: Institute for Employment Research, University of Warwick, 1996.

24 Resource allocation working party. Sharing resources for health in England, London: HMSO, 1976.

25 Smith P, Shaw R, Hauck K. Reducing avoidable inequalities in health: a new criterion for setting health care capitations. York: Centre for Health Economics, University of York, 2000.

26 Acheson D. Independent inquiry into inequalities in health. London: The Stationery Office Ltd, 1998.

27 Sheldon T, Smith P. Equity in the allocation of health care resources. Health Economics 2000; 9:571-4.

\section{News and notes}

\section{Call for abstracts: XVIth International Congress of the European Society for Philosophy of Medicine and Healthcare}

The theme of the XVIth International Congress of the European Society for Philosophy of Medicine and Healthcare is European Philosophy of Healthcare and Bioethics. The congress will be held in Malta from August 21 - 24, 2002. Abstracts should be received before December 1, 2001.
For more information please contact: Prof $\mathrm{dr}$ Henk ten Have, secretariat ESPMH, Department of Ethics, Philosophy and History of Medicine, University Medical Center, PO Box 9101, 6500 HB Nijmegen, the Netherlands. Fax: 024 - 3540254: from abroad: ++31-24-3540254. 